\title{
Decreased Myocardial Adenyl Cyclase Activity in Hypothyroidism
}

\author{
Gerald S. Levey, C. Lynn Skelton, and Stephen E. Epstein \\ From the Cardiology Branch, National Heart Institute, National Institutes of \\ Health, Bethesda, Maryland 20014
}

A B S T R A C T It has been suggested that hypothyroidism may alter the responsiveness of the heart to sympathetic stimulation. To define more precisely the interrelationship between hypothyroidism and catecholamine responsiveness we: (a) studied the effects of norepinephrine and fluoride on the activation of adenyl cyclase in the particulate fraction of heart homogenates from euthyroid and hypothyroid cats; and $(b)$ assessed the contractile response of isolated right ventricular papillary muscles from the same cats to increasing concentrations of norepinephrine. It was found that maximal accumulation of cyclic $3^{\prime}, 5^{\prime}$-adenosine monophosphate $\left(3^{\prime}, 5^{\prime}-\mathrm{AMP}\right)$ was significantly lower at peak norepinephrine concentrations in the hypothyroid ( $284 \pm 5$ pmoles) than in the euthyroid group (326 \pm 10 pmoles) $(P<$ $0.02)$. However, the $K_{m}$ for norepinephrine was similar in both groups (1-2 $\times 10^{-5}$ moles/liter $)$, and there was no apparent change in the threshold concentration. Fluoride-mediated increases in Cyclic $3^{\prime}, 5^{\prime}$-AMP accumulation were also significantly lower in the hypothyroid ( $585 \pm 25$ pmoles) as compared to the euthyroid group ( $790 \pm 20$ pmoles) $(P<0.02)$. In contrast, norepinephrine produced a similar augmentation of contractility in isolated papillary muscles from the hypothyroid and euthyroid cats. It thus appears that although the hypothyroid state is associated with a decrease in the total amount of myocardial adenyl cyclase per milligram of tissue capable of being activated by norepinephrine or fluoride, there is no change in the sensitivity of the enzyme to norepinephrine stimulation. Moreover, the finding that the inotropic response to norepinephrine is unaltered in hypothyroidism is compatible with the hypothesis that only a fraction of the total intracellular cyclic $3^{\prime}, 5^{\prime}$-AMP produced by norepinephrine activation of adenyl cyclase is required to elicit the inotropic response.

Received for publication 6 June 1969.

\section{INTRODUCTION}

The effects of thyroid hormone excess and deficiency on the sensitivity of the heart to catecholamine stimulation have been the subject of considerable study. Recent investigations have demonstrated that hyperthyroidism does not alter the responsiveness of the heart to the physiologic effects of sympathetic stimulation (1-4), nor does it alter the sensitivity of myocardial adenyl cyclase to norepinephrine stimulation (4). This latter finding is of importance since the physiologic effects of the catecholamines on the heart are believed to be mediated by an increase in intracellular levels of cyclic $3^{\prime}, 5^{\prime}$-AMP resulting from activation of adenyl cyclase (5).

Although the activity of myocardial adenyl cyclase in hypothyroidism is unknown, Krishna, Hynie, and Brodie demonstrated a decreased amount of adenyl cyclase in adipose tissue from hypothyroid rats (6), a change associated with a diminished responsiveness of adipose tissue to the lipolytic effects of norepinephrine. The data from early studies on the effects of hypothyroidism on the heart also suggested that sensitivity to the physiologic effects of sympathetic stimulation was depressed (7-9). However, these studies generally lacked adequate control groups and statistical analysis. More recent studies have demonstrated that catecholamine responsiveness of the heart was not altered by hypothyroidism $(2,3,10-12)$.

To define the interrelationship between cardiac catecholamine sensitivity and the hypothyroid state, we studied the effects of norepinephrine and fluoride on the activation of adenyl cyclase in the particulate fraction of heart homogenates from euthyroid and hypothyroid cats and correlated these data with the effects of norepinephrine on the contractile properties of isolated papillary muscles from the same cats. 


\section{METHODS}

Cats were made hypothyroid by a single intraperitoneal injection of $1 \mathrm{mc} / \mathrm{kg}^{281} \mathrm{I} 114-170$ days before study. At the time of sacrifice, blood was obtained for determination of protein-bound iodine and thyroxine by column chromatography.

The cats were anesthetized with intraperitoneal pentobarbital $(25-35 \mathrm{mg} / \mathrm{kg})$, and the heart was quickly removed. A right ventricular papillary muscle was excised and suspended in a muscle bath. The left ventricle was dissected free of endocardium and epicardium and used for the assay of adenyl cyclase activity.

Adenyl cyclase assay. A single cat from the euthyroid or hypothyroid group was used for each experiment. Approximately $220-250 \mathrm{mg}$ of left ventricular muscle was homogenized in $4.5 \mathrm{ml}$ of cold $0.25 \mathrm{M}$ sucrose with a motor-driven homogenizer at $1^{\circ} \mathrm{C}$. The homogenate was centrifuged at $10,000 \mathrm{rpm}$ for $10 \mathrm{~min}$ at $4^{\circ} \mathrm{C}$ and the supernatant fluid was decanted; the particles were washed with cold $0.25 \mathrm{M}$ sucrose and resuspended and recentrifuged at $10,000 \mathrm{rpm}$ for $10 \mathrm{~min}$. The washed particles were resuspended and homogenized in the cold $0.25 \mathrm{M}$ sucrose. Protein was determined by the method of Lowry, Rosebrough, Farr, and Randall (13) and adenyl cyclase was assayed by a recently developed method (14). The particulate fraction containing $0.05-0.10 \mathrm{mg}$ protein in a total volume of $0.06 \mathrm{ml}$ was incubated at $37^{\circ} \mathrm{C}$ for 3 min (except where noted in the text) with $1.6 \mathrm{~mm}$ ad enosine triphosphate (ATP), ATP_ ${ }^{\approx} \mathrm{P}, 1.1-1.5 \mu \mathrm{c} ; 8 \mathrm{mM}$ theophyl-

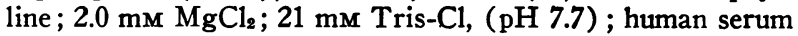
albumin, $0.8 \mathrm{mg} / \mathrm{ml}$; and $\mathrm{L}$-norepinephrine in concentrations ranging from $1 \times 10^{-8}$ to $5 \times 10^{-8}$ mole/liter. The incubations were started by adding the particulate fraction, which had been kept at $1^{\circ} \mathrm{C}$, to the other components which were at $23^{\circ} \mathrm{C}$. L-Norepinephrine was added to the particles just before the incubations were initiated. The incubations were stopped by adding $0.1 \mathrm{ml}$ of a solution containing $4 \mu$ moles of ATP, $1.25 \mu$ moles of cyclic $3^{\prime}, 5^{\prime}$-AMP, and $0.15 \mu \mathrm{c}$ of cyclic $3^{\prime}, 5^{\prime}-\mathrm{AMP}-{ }^{3} \mathrm{H}$ and they were boiled for $3 \mathrm{~min}$. The cyclic $3^{\prime}, 5^{\prime}-A M P-{ }^{3} \mathrm{H}$ served to determine the recovery of cyclic $3^{\prime}, 5^{\prime}$-AMP during the procedure; recoveries were $30-35 \%$. After boiling, $0.4 \mathrm{ml}$ of water was added, the precipitate removed by centrifugation and the supernate applied to a $0.5 \times 2.0 \mathrm{~cm}$ Dowex -50 column. The column was washed with water, and the eluate, between 3.0 and $6.0 \mathrm{ml}$, was collected and precipitated with $0.17 \mathrm{M} Z \mathrm{ZnSO}$ and $0.15 \mathrm{M}$ $\mathrm{Ba}(\mathrm{OH})_{2}$. The mixture was centrifuged and the cyclic $3^{\prime}, 5^{\prime}-A M P-{ }^{\infty} \mathrm{P}$ and cyclic $3^{\prime}, 5^{\prime}-\mathrm{AMP}-{ }^{\circ} \mathrm{H}$, which were in the supernatant, were then counted in a liquid scintillation spectrometer.

For the determination of phosphodiesterase activity, cyclic $3^{\prime}, 5^{\prime}$-AMP- ${ }^{8} \mathrm{H}$ (200 pmoles) was added to each reaction mixture. Incubation conditions were identical with those noted above except that theophylline, ATP- ${ }^{22} \mathrm{P}$, and norepinephrine were omitted. Cyclic $3^{\prime} 5^{\prime}-A M P$ was present at $1 \times 10^{-4}$ mole/liter. After boiling, the precipitate was removed by centrifugation; the supernatant was mixed with $3.4 \mathrm{ml}$ of water followed by $0.2 \mathrm{ml}$ of $0.15 \mathrm{M} \mathrm{Ba}(\mathrm{OH})_{2}$ and $0.2 \mathrm{ml}$ of $0.17 \mathrm{M} \mathrm{ZnSO}$. After centrifugation, $3 \mathrm{ml}$ of the supernatant was added to $17 \mathrm{ml}$ of Bray's solution and the radioactivity measured in a liquid scintillation spectrometer.

Papillary muscle preparation. Right ventricular papillary muscles were studied from 12 euthyroid cats and nine cats with induced hypothyroidism. The muscles were placed in a myograph previously described in detail (15). The bathing medium for all muscles was a modified Kreb's bicarbonate solution actively aerated with $95 \% \mathrm{O}_{2}$ and $5 \% \quad \mathrm{CO}_{2}$ at a constant temperature of $26^{\circ} \mathrm{C}$. Each muscle was allowed to equilibrate for $60 \mathrm{~min}$ contracting isometrically at a frequency of $12 / \mathrm{min}$. The length-active tension curve was determined for each muscle, and the muscle was subsequently maintained at the apex of this curve, $L_{\max }$. After an additional 30-60 min equilibration period to insure stability, the responsiveness of each muscle to increasing concentrations of L-norepinephrine $\left(10^{-10}\right.$ to $10^{-5}$ mole/liter $)$ was then determined at 5-min intervals, without washout between additions of the catecholamine. Isometric contractile function was measured during the control period and after each addition of norepinephrine. Tension was corrected for cross-sectional area and expressed in grams per square millimeter. Mean cross-sectional area of the muscles from the euthyroid cats $\left(0.84 \pm 0.10 \mathrm{~mm}^{2}\right)$ was somewhat greater than that of the hypothyroid group $\left(0.71 \pm 0.08 \mathrm{~mm}^{2}\right)$, but this difference was not statistically significant.

Results are expressed as the mean ISEM. Statistical tests of significance were performed utilizing Student's $t$ test for paired and unpaired data where applicable.

\section{RESULTS}

Characterization of thyroid state. Thyroid ablation with ${ }^{181} \mathrm{I}$ resulted in a marked lowering of serum protein-bound iodine in all treated cats. Protein-bound iodine levels were $4.7 \pm 0.3 \mu \mathrm{g} / 100 \mathrm{ml}$ before ${ }^{201}$ I treatment compared to $1.8 \pm 0.3 \mu \mathrm{g} / 100 \mathrm{ml}(P<0.01)$ at the time of sacrifice. $24-\mathrm{hr}{ }^{128} \mathrm{I}$ uptake studies performed in six of the treated animals 90 days after administration of $1 \mu \mathrm{c} / \mathrm{kg}{ }^{131} \mathrm{I}$ demonstrated an average uptake of 2.3 $\pm 0.9 \%$ compared to an uptake of $30.1 \pm 7.7 \%$ in three euthyroid cats $(P<0.01)$. Serum thyroxine levels measured by column chromatography were significantly lower in the hypothyroid cats, $0.6 \pm 0.1 \mu \mathrm{g} / 100 \mathrm{ml}$, than in the euthyroid animals, $3.0 \pm 0.5 \mu \mathrm{g} / 100 \mathrm{ml}(P<$ 0.01 ). No thyroid gland tissue could be identified at postmortem examination in any of the ${ }^{181}$ I-treated cats, although thyroid tissue was easily identified in the euthyroid animals. Average body weight was greater in the hypothyroid animals, $3.10 \pm 0.15 \mathrm{~kg}$, than in the euthyroid group, $2.62 \pm 0.09 \mathrm{~kg}(P<0.01)$. However, ventricular weight was similar in the two groups (euthyroid $6.68 \pm 0.33 \mathrm{~g}$; hypothyroid $6.44 \pm 0.36 \mathrm{~g}$, NS). Thus, the ventricular weight $(\mathrm{g})$ /body weight $(\mathrm{kg})$ ratio was less in the hypothyroid cats, 2.07 , than in the euthyroid animals, 2.52 .

Effects of increasing doses of norepinephrine on adenyl cyclase activity. There was no difference between the control values of adenyl cyclase activity measured in tissue obtained from euthyroid and hypothyroid animals. Activation of adenyl cyclase produced by norepinephrine was concentration related; however, accumulation of cyclic $3^{\prime}, 5^{\prime}$-AMP was significantly lower in the hypothyroid compared to the euthyroid group at each point on the dose-response curve (Fig. 1). In addition, the peak levels of cyclic 3',5'-AMP accumulation that could be achieved were also significantly lower in the hypothyroid group, $284 \pm 5$ pmoles, than in the euthyroid, 
$326 \pm 10$ pmoles $(P<0.02)$. The estimated $K_{m}$ for norepinephrine was similar in the two groups, $1 \times 10^{-5}$ mole/liter in the euthyroid and $2 \times 10^{-5}$ mole/liter in the hypothyroid.

Effects of fluoride on adenyl cyclase activity. Fluoride activates adenyl cyclase to a level thought to represent total adenyl cyclase activity (16). Activation of adenyl cyclase by fluoride was found to be maximal over a concentration range of 4-10 mmoles/liter in both the euthyroid and hypothyroid groups. However, activation of adenyl cyclase by $8 \mathrm{~mm}$ fluoride in the particulate preparations (Fig. 2) and in crude homogenates from the hypothyroid cats was significantly less than in the euthyroid.

Norepinephrine activation of adenyl cyclase as a function of time. Activation of adenyl cyclase by norepinephrine as a function of time was unaltered by the hypothyroid state with maximal activation in this system occurring at $5 \mathrm{~min}$ in both groups (Fig. 3 ). However, throughout the time course of incubation total cyclic $3^{\prime}, 5^{\prime}$-AMP production was less in the hypothyroid group as compared with the euthyroid.

Phosphodiesterase activity. Phosphodiesterase catalyzes the degradation of cyclic $3^{\prime}, 5^{\prime}$-AMP to $5^{\prime}$-AMP. Therefore, an increase in the activity of this enzyme could account for the decreased accumulation of cyclic $3^{\prime}, 5^{\prime}$-AMP in hearts from hypothyroid animals. However, phosphodiesterase activity in hypothyroidism was unaltered from the euthyroid both in the particulate preparations and in the original crude cat heart homogenates (Table I).
Myocardial mechanics. The analysis of isometric contractions of right ventricular papillary muscles at the apex of the length-active tension curve revealed significant differences between the euthyroid and hypothyroid groups. Active tension averaged $5.8 \pm 0.4 \mathrm{~g} / \mathrm{mm}^{2}$ in muscles from 12 euthyroid cats and $4.4 \pm 0.5$ in muscles from nine hypothyroid cats $(P<0.05)$. In addition, the maximal rate of tension development averaged $17.4 \pm 1.6 \mathrm{~g} / \mathrm{mm}^{2}$ per sec in muscles obtained from euthyroid cats and $12.1 \pm 1.2 \mathrm{~g} / \mathrm{mm}^{2}$ per sec $(P<0.02)$ in those from hypothyroid animals. No significant difference in time-to-peak tension was found between the two groups (euthyroid $601 \pm 23 \mathrm{msec}$; hypothyroid $611 \pm 13 \mathrm{msec}$ ). Thus, the isometric contractile function of the heart in hypothyroidism is depressed from normal and is characterized by a decrease in both the rate and magnitude of tension development.

The contractile response of papillary muscles from nine hypothyroid and 12 euthyroid cats after exposure to concentrations of norepinephrine ranging from $10^{-10}$ to $10^{-5}$ mole/liter is shown in Fig. 4. No significant differences were found in the contractile response of muscles from the euthyroid and hypothyroid groups at any point on the norepinephrine concentration-response curve, whether the absolute increases in active tension or absolute increases in rate of tension development were compared.

To ensure that the minor differences in muscle crosssectional area between the euthyroid and hypothyroid groups did not account for the equivalence in the contractile response to norepinephrine, we compared the

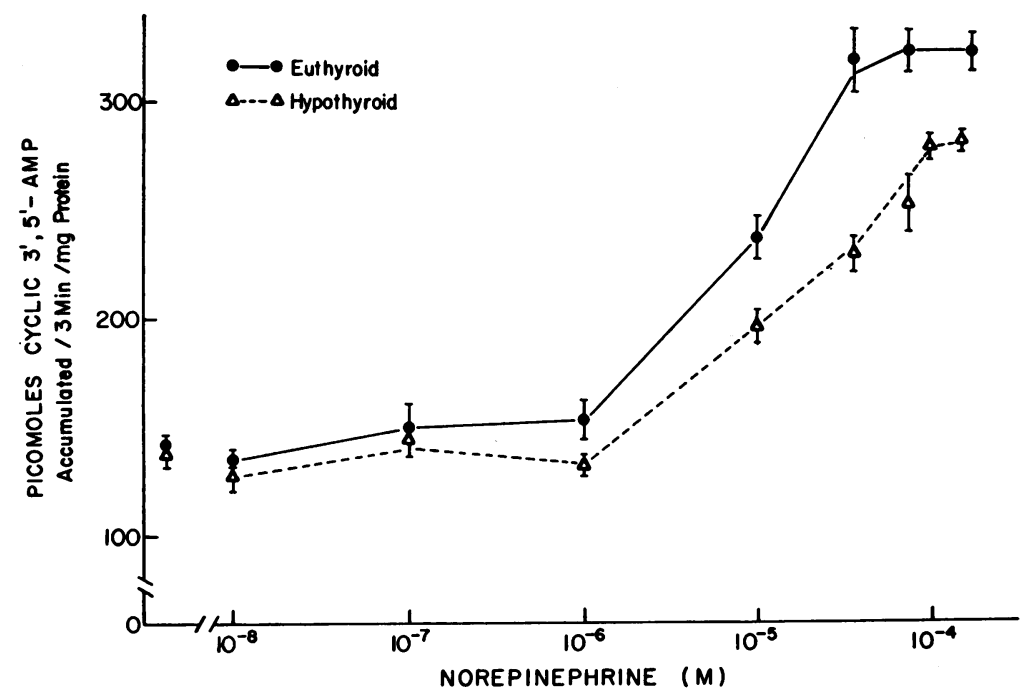

FIGURE 1 Norepinephrine concentration-response curves in the particulate fraction of heart homogenates from euthyroid and hypothyroid cats. The values represent the mean \pm SE of 10-15 samples from six cats. The differences are significant at: $1 \times 10^{-5}$ mole/liter $(P<0.05) ; 5 \times 10^{-5}$ mole/liter $(P<0.02) ; 8 \times 10^{-5}$ mole/liter $(P<0.02) ; 1-2 \times 10^{-4}$ mole $/$ liter $(P<0.05)$. 


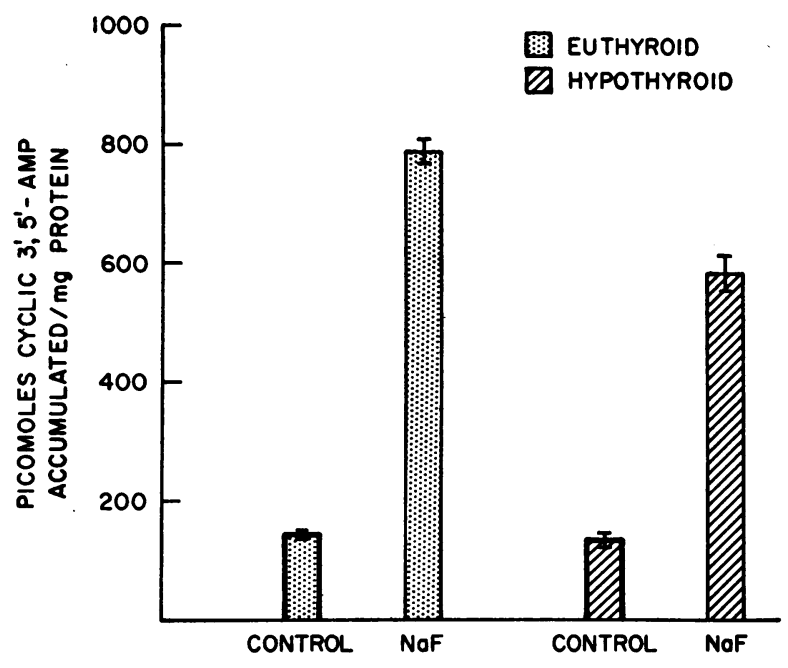

FIGURE 2 Fluoride activation of adenyl cyclase in the particulate fraction of heart homogenates from euthyroid and hypothyroid cats. The values represent the mean $\pm S E$ of five samples. Fluoride was present at its maximal concentration of $8 \mathrm{mmoles} / \mathrm{liter}$. Significantly less cyclic $3^{\prime}, 5^{\prime}$-AMP was accumulated after fluoride activation in the hypothyroid preparation $(P<0.02)$.

results obtained from five muscles from each group matched for cross-sectional area. These five pairs of muscles were the only ones in which such matching of cross-sectional areas was possible. Again no significant difference in the contractile response to norepinephrine was observed between the euthyroid and hypothyroid animals.

\section{DISCUSSION}

Catecholamines are thought to exert their positive inotropic effects by increasing the intracellular level of cyclic $3^{\prime}, 5^{\prime}$-AMP through activation of myocardial adenyl cyclase. This hypothesis is supported by the following observations: $(a)$ the relative potencies of a series of catecholamines in stimulating adenyl cyclase in broken-cell preparations from dog heart are similar to their relative potencies as inotropic agents in vivo, and both these effects are prevented by beta-receptor blockade (17); (b) tissue levels of cyclic $3^{\prime}, 5^{\prime}$-AMP in intact heart muscle increase in response to catecholamine stimulation (18-21); and $(c)$ the exogenous administration of dibutyryl cyclic $3^{\prime}, 5^{\prime}$-AMP causes a positive inotropic response in cat papillary muscle. ${ }^{1}$

The results of this investigation demonstrate that the activity of myocardial adenyl cyclase is altered by hypothyroidism. Accumulation of cyclic 3',5'-AMP was significantly lower at maximal norepinephrine concen-

\footnotetext{
${ }^{1}$ Skelton, C. L., G. S. Levey, and S. E. Epstein. Positive inotropic effects of dibutyryl cyclic AMP. Submitted for publication.
}

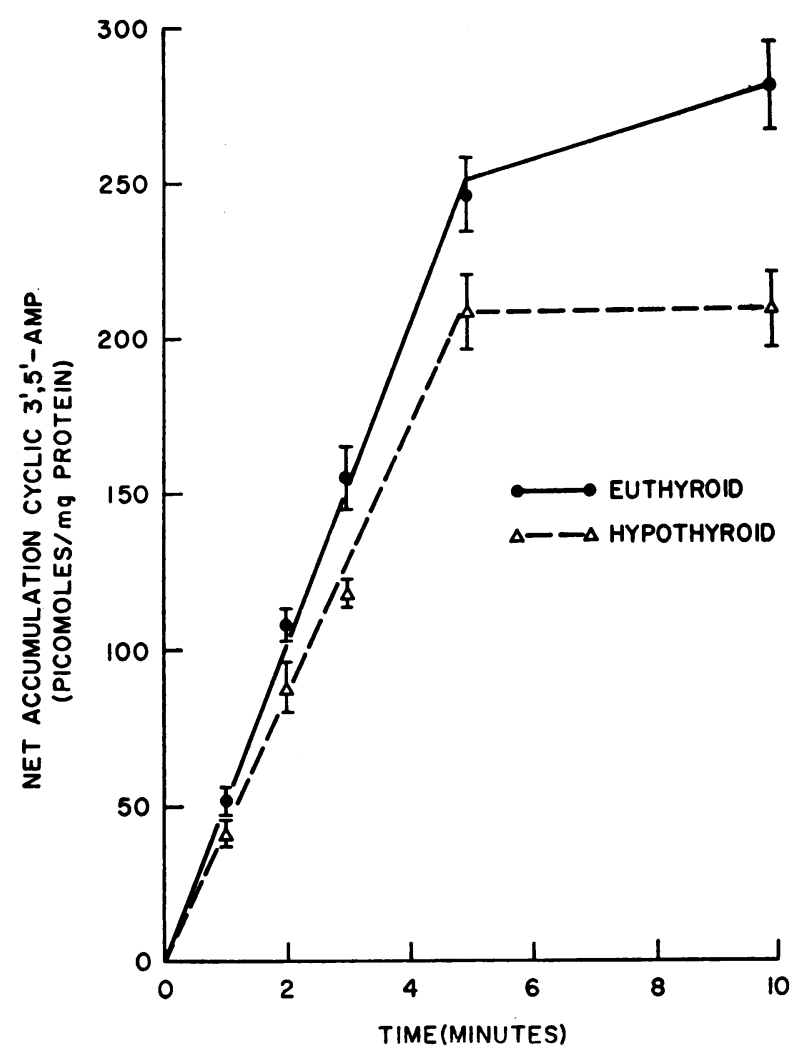

FIGURE 3 Net accumulation of cyclic $3^{\prime}, 5^{\prime}$-AMP in the particulate fraction of heart homogenates from euthyroid and hypothyroid cats produced by norepinephrine as a function of time. The values represent the mean $\pm S E$ of three to six samples of two cats. Norepinephrine was present at a concentration of $5 \times 10^{-8}$ mole/liter.

trations in the preparations obtained from the hearts of hypothyroid animals. However, there was no appreciable shift in the $K_{m}$ for norepinephrine, nor any change in its threshold concentration. These data indicate that

TABLE I

Phosphodiesterase Activity

\begin{tabular}{lc}
\hline & Cyclic 3',5'-AMP \\
\hline A. Particles & pmoles hydrolyzed/3 min \\
Euthyroid & $2.7 \pm 2.0$ \\
Hypothyroid & $3.0 \pm 2.3$ \\
B. Homogenate & \\
Euthyroid & $39.0 \pm 1.8$ \\
Hypothyroid & $41.0 \pm 2.2$
\end{tabular}

Phosphodiesterase activity in the particulate fraction and crude homogenate of hearts from euthyroid and hypothyroid cats. Each value represents the mean $\pm \mathrm{SE}$ of six to nine samples. 


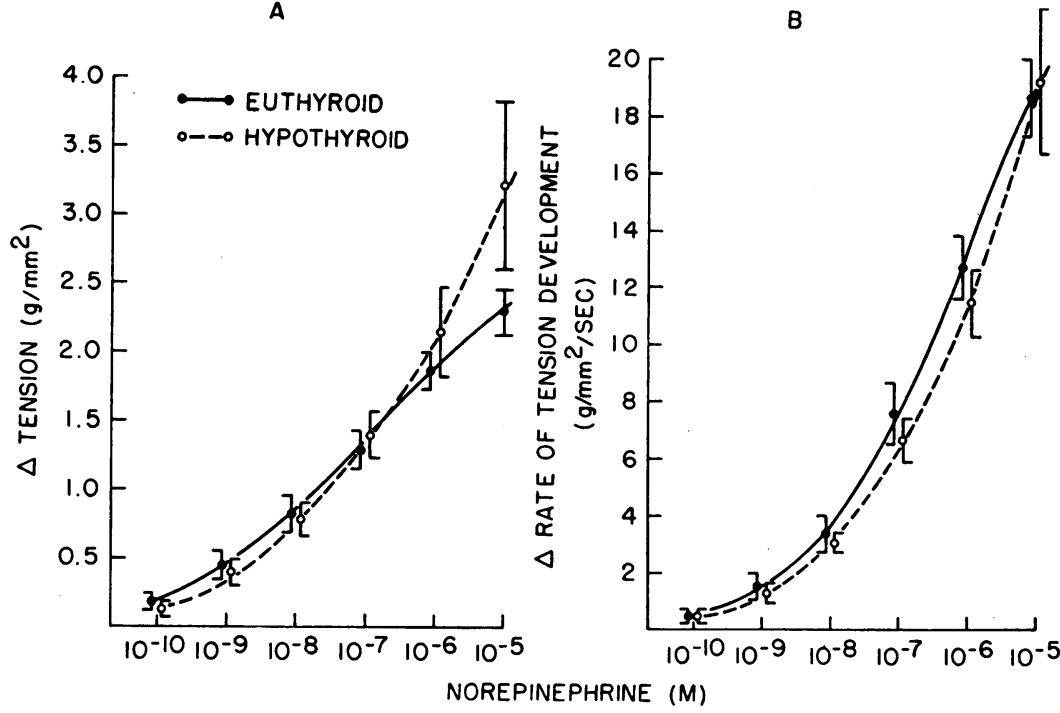

FIgURE 4 The effects of norepinephrine on isometric tension and rate of tension development in papillary muscles from 12 euthyroid and nine hypothyroid cats. The average increment in tension (A) and increment in rate of tension (B) are plotted as a function of norepinephrine concentration. Contraction frequency was $12 / \mathrm{min}$.

the sensitivity of myocardial adenyl cyclase to norepinephrine was unaltered by hypothyroidism, although the total activity of enzyme per milligram tissue was decreased. Moreover, activation of adenyl cyclase by a concentration of fluoride producing a maximal effect in tissue from both euthyroid and hypothyroid cats was also markedly decreased in the preparations from the hypothyroid group. This finding is also consistent with the hypothesis that the total activity of adenyl cyclase per unit of myocardial tissue is depressed in hypothyroidism, since fluoride is believed to be capable of maximally activating this enzyme (16).

The differences in the responses of adenyl cyclase to norepinephrine found in the particulate preparations were also observed in the original crude homogenates. It is thus unlikely that the depression in enzyme activity is merely due to a hypothyroid-induced alteration in the sedimentation characteristics of the cellular membranes. In addition, the time course of each reaction was linear for $5 \mathrm{~min}$ at which point maximal activation of adenyl cyclase occurred in both the euthyroid and hypothyroid groups. The accumulation of cyclic $3^{\prime}, 5^{\prime}$-AMP was lower in the hypothyroid preparation at every point on the time curve. Therefore, the diminished response of adenyl cyclase to norepinephrine and fluoride observed during the standard $3 \mathrm{~min}$ incubation could not have been due to changes in the time required for maximal activation of the enzyme.

Since phosphodiesterase catalyzes the degradation of cyclic $3^{\prime}, 5^{\prime}$-AMP to $5^{\prime}$-AMP, an increase in phospho- diesterase activity could have been responsible for the diminished accumulation of cyclic $3^{\prime}, 5^{\prime}$-AMP. However, assay of phosphodiesterase activity in both the crude homogenate and particulate preparations disclosed no differences between the euthyroid and hypothyroid tissues. These results demonstrate that in contrast to the hyperthyroid state in which no alteration in the characteristics of myocardial adenyl cyclase was found (4), hypothyroidism causes a decrease in the peak response of myocardial adenyl cyclase to norepinephrine and fluoride stimulation, a change most likely resulting from a reduction in the total amount of enzyme per milligram of tissue.

On the basis of these findings it might have been expected that the cardiac effects of the catecholamines would be diminished in hypothyroidism. Indeed, several early studies suggested that hypothyroidism does reduce the responsiveness of the heart to catecholamine stimulation (7-9). Recent reports, however, have failed to confirm these findings. Margolius and Gaffney found similar inotropic and chronotropic responses to exogenously administered norepinephrine and to several frequencies of cardiac sympathetic nerve stimulation in euthyroid and hypothyroid dogs (2). In addition, investigations by Benforado and Wiggins on the chronotropic effects of norepinephrine on isolated atria from euthyroid and hypothyroid dogs (10), by Leak and Lew on cardiac responses to graded doses of intravenous epinephrine in hypothyroid patients before and after treatment with thyroid hormone (11), and by 
Wurtman, Kopin, and Axelrod on the effects of epinephrine on mean blood pressure responses in euthyroid and hypothyroid rats (12), all demonstrated that the cardiovascular system in hypothyroidism responded in a normal manner to catecholamines. Most recently, Buccino and coworkers examined the inotropic effects of norepinephrine on isolated right ventricular papillary muscles from euthyroid and hypothyroid cats (3). These investigators found that the muscles obtained from hypothyroid cats did not exhibit any decreased responsiveness to norepinephrine. The results in the present study using a similar papillary muscle preparation confirm the previous findings.

It is of interest that in the present study the papillary muscles that exhibited a normal inotropic response to norepinephrine were obtained from the same hearts in which a decreased responsiveness of adenyl cyclase to norepinephrine stimulation was demonstrated. Relevant to these findings is the study of Grahame-Smith, Butcher, Ney, and Sutherland (22) which demonstrated that in the adrenal gland maximal steroidogenesis was produced by a dose of adrenocorticotropic hormone $(\mathrm{ACTH})$ that produced only a fraction $(<1 \%)$ of the total intracellular cyclic $3^{\prime}, 5^{\prime}$-AMP that could be produced by higher doses of ACTH. Although a true plateau in the concentration-response curve to norepinephrine could not be attained because of the appearance of spontaneous contractions at concentrations greater than $10^{-5} \mathrm{~mole} / \mathrm{liter}$, it would appear that the amount of adenyl cyclase capable of being activated by norepinephrine in the heart is in excess of that needed to elicit the maximal attainable inotropic response.

It should be noted that the threshold concentration of norepinephrine that activates adenyl cyclase in the particulate heart preparations is several orders of magnitude greater than that required to elicit an inotropic response in the isolated papillary muscle. This decreased sensitivity of adenyl cyclase has been observed previously by other workers in both cardiac (17) and other tissues $(23,24)$. The explanation for this finding is unclear.

In summary, the results of this investigation demonstrate that hypothyroidism, experimentally induced in cats, is associated with a decrease in the total activity of myocardial adenyl cyclase per milligram of tissue. The sensitivity of this enzyme to norepinephrine stimulation appears to be unaltered. Despite the decrease in total cardiac adenyl cyclase, isolated papillary muscles from hypothyroid cats respond normally to norepinephrine. These data are compatible with the hypothesis that only a portion of the cyclic $3^{\prime}, 5^{\prime}$-AMP produced by activation of adenyl cyclase by a given concentration of norepinephrine is needed to elicit the physiologic response.

\section{ACKNOWLEDGMENT}

We are grateful to Mrs. Hope Cook for her expert technical assistance.

\section{REFERENCES}

1. Van der Schoot, J. B., and N. C. Moran. 1965. An experimental evaluation of the reputed influence of thyroxine on the cardiovascular effects of catecholamines. $J$. Pharmacol. Exp. Ther. 149: 336.

2. Margolius, H. S., and T. E. Gaffney. 1965. The effects of injected norepinephrine and sympathetic nerve stimulation in hypothyroid and hyperthyroid dogs. J. Pharmacol. Exp. Ther. 149: 329.

3. Buccino, R. A., J. F. Spann, Jr., P. E. Pool, E. H. Sonnenblick, and E. Braunwald. 1967. Influence of the thyroid state on the intrinsic contractile properties and energy stores of the myocardium. J. Clin. Invest. 46: 1669.

4. Levey, G. S., C. L. Skelton, and S. E. Epstein. The influence of hyperthyroidism on the effects of norepinephrine on myocardial adenyl cyclase activity and contractile state. Endocrinology. In press.

5. Sutherland, E. W., and G. A. Robison. 1966. Metabolic effects of catecholamines. A. The role of cyclic $3^{\prime}, 5^{\prime}$-AMP in responses to catecholamines and other hormones. Pharmacol. Rev. 18: 145.

6. Krishna, G., S. Hynie, and B. B. Brodie. 1968. Effects of thyroid hormones on adenyl cyclase in adipose tissue and on free fatty acid mobilization. Proc. Nat. Acad. Sci. U. S. A. 59: 884 .

7. Eppinger, E. C., and S. A. Levine. 1934. Effect of total thyroidectomy on response to adrenalin. Proc. Soc. Exp. Biol. Med. 31: 485.

8. Hoffmann, F., E. J. Hoffmann, and J. Talesnik. 1947. Influence of the thyroid hormone on the effector systems of the mammalian heart. Amer. J. Physiol. 148: 689.

9. Schneckloth, R. E., G. S. Kurland, and A. S. Freedberg. 1953. Effect of variation in thyroid function on the pressor response to norepinephrine in man. Metabolism. 2 546.

10. Benforado, J. M., and L. L. Wiggins. 1965. Contractility, heart rate, and response to norepinephrine of isolated rat myocardium following $I^{120}$-induced hypothyroidism. J. Pharmacol. Exp. Ther. $147: 70$.

11. Leak, D., and M. Lew. 1963. Effect of treatment of hypothyroidism on circulatory response to adrenaline. Brit. Heart J. 25: 30 .

12. Wurtman, R. J., I. J. Kopin, and J. Axelrod. 1963. Thyroid function and the cardiac disposition of catecholamines. Endocrinology. 73: 63.

13. Lowry, O. H., N. J. Rosebrough, A. L. Farr, and R. J. Randall. 1951. Protein measurement with the folin phenol reagent. J. Biol. Chem. 193: 265.

14. Krishna, G., B. Weiss, and B. B. Brodie. 1968. A simple sensitive method for the assay of adenyl cyclase. J. Pharmacol. Exp. Ther. 163: 379.

15. Pool, P. E., and E. H. Sonnenblick. 1967. The mechanochemistry of cardiac muscle. I. The isometric contraction. J. Gen. Physiol. 50: 951.

16. Sutherland, E. W., T. W. Rall, and T. Menon. 1962. Adenyl cyclase. I. Distribution, preparation, and properties. J. Biol. Chem. 237: 1220.

17. Murad, F., Y. M. Chi, T. W. Rall, and E. W. Sutherland. 1962. Adenyl cyclase. III. Effect of catecholamines and choline esters on the formation of adenosine $3^{\prime}, 5^{\prime}$ - 
phosphate by preparations from cardiac muscle and liver. J. Biol. Chem. 237: 1233.

18. Robison, G. A., R. W. Butcher, I. Øye, H. E. Morgan, and E. W. Sutherland. 1965. The effect of epinephrine on adenosine $3^{\prime}, 5^{\prime}$-phosphate levels in the isolated perfused rat heart. Mol. Pharmacol. 1: 168.

19. Cheung, W. Y., and J. R. Williamson. 1965. Kinetics of cyclic adenosine monophosphate changes in rat heart following epinephrine administration. Nature (London). 207: 979.

20. Hammermeister, K. E., A. A. Yunis, and E. G. Krebs. 1965. Studies on phosphorylase activation in the heart. J. Biol. Chem. 240: 986.

21. Drummond, G. I., L. Duncan, and E. Hertzman. 1966.
Effect of epinephrine on phosphorylase b kinase in perfused rat hearts. J. Biol. Chem. 241: 5899.

22. Grahame-Smith, D. G., R. W. Butcher, R. L. Ney, and E. W. Sutherland. 1967. Adenosine $3^{\prime}, 5^{\prime}$-monophosphate as the intracellular mediator of the action of adrenocorticotropic hormone on the adrenal cortex. J. Biol. Chem. 242: 5535 .

23. Taunton, O. D., J. Roth, and I. Pastan. 1969. Studies on the adrenocorticotropic hormone-activated adenyl cyclase of a functional adrenal tumor. J. Biol. Chem. 244: 247.

24. Pastan, I., and R. Katzen. 1967. Activation of adenyl cyclase in thyroid homogenates by thyroid-stimulating hormone. Biochem. Biophys. Res. Commun. 29: 792. 